\title{
Plasma carotenoid concentrations in relation to acute respiratory infections in elderly people
}

\author{
Judith M. van der Horst-Graat, Frans J. Kok and Evert G. Schouten* \\ Division of Human Nutrition and Epidemiology, Wageningen University, Bomenweg 2, P.O. Box 8129, 6703 HD, \\ Wageningen, The Netherlands
}

(Received 16 September 2003 - Revised 14 February 2004 - Accepted 29 February 2004)

\begin{abstract}
A high plasma carotenoid concentration could improve the immune response and result in decreased risk of infectious diseases. However, data on the relationship of plasma carotenoid concentration with acute respiratory infections, which occur frequently in elderly people, are scarce. We investigated, therefore, the relationship of plasma concentrations of six major carotenoids ( $\beta$-carotene, $\alpha$-carotene, $\beta$-cryptoxanthin, lycopene, lutein and zeaxanthin) with the incidence and severity of acute respiratory infections. Baseline data from an intervention trial were used. Participants were 652 non-institutionalized elderly people ( $\geq 60$ years old) enrolled via two community-based sampling strategies in the Wageningen area of The Netherlands in 1998-99. Plasma carotenoid concentrations were divided into quartiles, the lowest being the reference. Frequency and severity of episodes during the previous 1 year, i.e. staying in bed, medical consultation and episode-related medication, were self-reported by means of a questionnaire. On average 1.6 episodes per person were recorded. The incidence rate ratio of acute respiratory infections at high $\beta$-carotene status was 0.71 (95\% CI 0.54-0.92) as compared with the low $\beta$-carotene concentration group. No association was observed between $\beta$-carotene and illness severity. $\alpha$-Carotene, $\beta$-cryptoxanthin, lycopene, lutein and zeaxanthin were not related to incidence or severity of the infections. We conclude that elderly people with a high plasma $\beta$-carotene concentration may have a lower occurrence of acute respiratory infections.
\end{abstract}

Acute respiratory infection: Carotenoids: Elderly people

Elderly people are at high risk of morbidity from infections, especially from respiratory infections, which occur frequently (Miller, 1996). On average, community-dwelling elderly people suffer from one to two acute respiratory infections per year (Nicholson et al. 1997; Graat et al. 2002).

$\beta$-Carotene, $\alpha$-carotene, $\beta$-cryptoxanthin, zeaxanthin, lycopene and lutein comprise approximately $90 \%$ of the total plasma pool of carotenoids (Thurnham, 1994; Vogel et al. 1997). $\beta$-Carotene has been studied extensively in relation to immune response, whereas for other carotenoids such information is scarce (Jyonouchi et al. 1996; Hughes et al. 2000; Corridan et al. 2001). Some studies have shown an enhanced immune response at high plasma $\beta$ carotene status or after $\beta$-carotene supplementation (Watson et al. 1991; Fuller et al. 1992; van-Poppel et al. 1993; Murata et al. 1994; Santos et al. 1996; Hughes, 2001), whereas others have not (Ringer et al. 1991; Daudu et al. 1994; Murata et al. 1994; Santos et al. 1997; Corridan et al. 2001). Only one study has investigated acute respiratory infections, i.e. common cold incidence, in relation to both dietary $\beta$-carotene intake and supplementation in male smokers. High intake was associated with a slightly higher cold incidence, whereas supplementation had no effect on incidence (Hemila et al. 2002). The antioxidant properties and modulating effect on prostaglandin $E_{2}$ production of $\beta$-carotene might explain its possible beneficial effects (Khachik et al. 1995; Hughes, 2001).

Although clinical endpoints such as infectious diseases have much greater public health relevance than immune function, they have hardly been studied until now. The aim of our present study was to investigate the relationship between plasma carotenoid concentrations and acute respiratory infections during 1997-98 in elderly persons. We investigated the incidence of illness and severity in relation to $\beta$-carotene, $\alpha$-carotene, $\beta$-cryptoxanthin, lycopene, lutein and zeaxanthin.

\section{Methods \\ Subjects}

Subjects were approached to participate in a 15-month double-blind intervention trial investigating the effect of daily micronutrients on acute respiratory infections. According to the $2 \times 2$ factorial design, participants were randomly assigned to the following groups using blocked randomization: $200 \mathrm{mg} \mathrm{d} 1-\alpha$-tocopheryl acetate; a physiological dose of multivitamins-minerals; $200 \mathrm{mg}$ d1- $\alpha$-tocopheryl acetate plus a physiological dose of multivitamins-minerals; 
placebo. The present study has been described in detail by Graat et al. (2002).

We used the baseline information of our present study population for this retrospective study concerning carotenoid status and respiratory infections in the previous 1 year. The study population included 652 participants: 325 men and 327 women. All persons were $\geq 60$ years old, with an average age of 73 years. Only $2 \%$ of the subjects lived in homes for the aged. We therefore consider that our present study population were non-institutionalized. Participants had no history of cancer, liver disease or fat malabsorption in the 5 years before enrolment. A questionnaire was used to ask for nutritional supplementation during the previous year. Written informed consent was obtained from all participants before participation. The medical ethics committee of Wageningen University, The Netherlands, approved the research protocol.

\section{Respiratory infections}

The main outcomes were incidence and severity of acute respiratory infections during the previous year. At the time of blood collection, which was between 1 September 1998 and 23 March 1999, a detailed questionnaire about respiratory infections during the previous 12 months was filled out by all participants, with the help of a research assistant. Therefore, the recorded infections took place in 1997-98. Participants were asked about the frequency of common cold, influenza, pneumonia, sore throat and pain in facial sinuses. These different manifestations of infection were combined and simply referred to as 'acute respiratory infection' for two reasons: (1) it is difficult to distinguish between upper and lower respiratory infections, because the symptom patterns can be indistinguishable (Tannock et al. 1993; Nicholson et al. 1997; Carrat et al. 1999); (2) lower respiratory tract symptoms were reported to complicate $65 \%$ of upper respiratory tract infections (Nicholson et al. 1997). For each past episode of acute respiratory infection, information on illness severity, i.e. staying in bed (in bed for several hours because of infection-related symptoms at a time that one would not usually stay in bed), medical consultation (visit a general practitioner or other physician because of infection-related symptoms) and use of medication (any medication, including antibiotics, prescribed by a general practitioner or other physician), were also recorded in the questionnaire.

\section{Analysis of carotenoids}

Between 1 September 1998 and 23 March 1999 blood samples were drawn to determine the plasma concentrations of cis- $\beta$-carotene, trans- $\beta$-carotene, $\alpha$-carotene, $\beta$-cryptoxanthin, lycopene, lutein and zeaxanthin. The $\beta$-carotene concentration was calculated from the sum of cis- $\beta$-carotene and trans- $\beta$-carotene values. Concentrations of retinol, $\alpha$-tocopherol and ascorbic acid were also determined. Samples were collected between 08.30 and 11.00 hours. A light breakfast, without salads, fruits or fruit juices, was allowed before sampling. None of the subjects had been taking any nutritional supplementation in the 2 months before blood drawing. Plasma was immediately stored on ice in a closed box, and, within $6 \mathrm{~h}$ of blood collection, stored at $-80^{\circ} \mathrm{C}$. The reversed-phase HPLC method was used to analyse fat-soluble vitamin concentrations (Hess et al. 1991; Aebischer et al. 1999). Ascorbic acid concentration was obtained via standard procedures and assessed by fluorimetric assay (Vuilleumier \& Keck, 1989).

\section{Statistical analyses}

Participants were divided into quartiles of plasma carotenoid concentrations. The two middle quartiles, i.e. $25-75$ th, were collapsed and referred to as intermediate carotenoid status'. The low-carotenoid class was taken as the reference group. Frequencies including percentages were calculated for categorical data and were compared by $\chi^{2}$ test or Fisher's exact test. Continuous variables were compared by ANOVA for unbalanced data by the SAS procedure GLM (SAS version 8; SAS Institute, Cary, NC, USA) and were expressed as mean values and standard deviations.

To calculate incidence rate ratios of the infections, a Poisson regression model was used with the number of episodes as the dependent variable and the carotenoid status as the independent variable included in the model. Because some carotenoids possess pro-vitamin A activity, the relationship between vitamin A (retinol) and incidence of the infections was assessed.

Because we assumed that all carotenoids could have the same beneficial effect on the infections, all carotenoids were combined in a Poisson regression model to investigate whether the relative risk of such combination differed from the results of $\beta$-carotene only.

Logistic regression was used to calculate adjusted odds ratios and the corresponding $95 \%$ CI for the severity outcomes. Illness severity was assessed in participants who experienced at least one acute respiratory infection.

The variables age, BMI, self-rated health (score 1-10, 10 indicating highest self-rated health), retinol, $\alpha$-tocopherol and ascorbic acid status, gender, chronic obstructive pulmonary disease, asthma, influenza vaccination, history of nutritional supplementation and smoking (current, former, never) were evaluated for confounding and effect modification. If variables were related to the carotenoid status and to the incidence of infection, they were entered into the model. Depending on the carotenoid investigated, gender, age, BMI, self-rated health and chronic obstructive pulmonary disease turned out to be confounders. Inclusion of age or gender into the models precluded adjustment for BMI, because of multicollinearity between gender or age and BMI. No effect modifiers turned out to influence the relationships.

\section{Results}

Population characteristics and plasma (pro-) vitamin concentrations of participants at high, intermediate and low $\beta$-carotene status are described in Table 1. Similar characteristics were observed for the $\alpha$-carotene, $\beta$-cryptoxanthin, lycopene, lutein and zeaxanthin, and are therefore not shown. The correlation between $\beta$-carotene and $\alpha$-carotene was 0.78 and between zeaxanthin and 
Table 1. Population characteristics and plasma concentrations of carotenoids and vitamins in 652 elderly Dutch subjects by $\beta$-carotene concentration*

(Mean values and standard deviations)

\begin{tabular}{|c|c|c|c|c|c|c|}
\hline \multirow[b]{2}{*}{$\beta$-Carotene... } & \multicolumn{2}{|c|}{ High ( $n$ 162) } & \multicolumn{2}{|c|}{$\begin{array}{l}\text { Intermediate } \\
\quad(n 325)\end{array}$} & \multicolumn{2}{|c|}{ Low $(n$ 165) } \\
\hline & Mean & SD & Mean & SD & Mean & SD \\
\hline \multicolumn{7}{|l|}{ Population characteristics } \\
\hline Men (\%) & \multicolumn{2}{|c|}{$37 \cdot 0$} & \multicolumn{2}{|c|}{$47 \cdot 1$} & \multicolumn{2}{|c|}{67.9} \\
\hline Age (years) & 74.0 & $7 \cdot 1$ & 73.6 & 6.9 & $72 \cdot 2$ & $6 \cdot 7$ \\
\hline $\mathrm{BMI}\left(\mathrm{kg} / \mathrm{m}^{2}\right)$ & $25 \cdot 9$ & $3 \cdot 3$ & 27.5 & $3 \cdot 4$ & $28 \cdot 4$ & $3 \cdot 7$ \\
\hline Self-rated health (score 1 (lowest) -10 ) & $7 \cdot 6$ & 0.9 & 7.5 & 1.1 & $7 \cdot 2$ & $1 \cdot 2$ \\
\hline Chronic obstructive pulmonary disease (\%) & \multicolumn{2}{|c|}{4.3} & \multicolumn{2}{|c|}{$9 \cdot 5$} & \multicolumn{2}{|c|}{$17 \cdot 0$} \\
\hline Asthma (\%) & \multicolumn{2}{|c|}{1.9} & \multirow{2}{*}{\multicolumn{2}{|c|}{$\begin{array}{r}2 \cdot 8 \\
20.0\end{array}$}} & \multicolumn{2}{|c|}{1.8} \\
\hline Allergy $(\%) \dagger$ & \multicolumn{2}{|c|}{$17 \cdot 3$} & & & \multicolumn{2}{|c|}{$18 \cdot 2$} \\
\hline Current smoker (\%) & \multirow{2}{*}{\multicolumn{2}{|c|}{$\begin{array}{r}8.0 \\
75.2\end{array}$}} & \multicolumn{2}{|c|}{9.9} & & \\
\hline Influenza vaccination (\%) & & & \multicolumn{2}{|c|}{74.9} & \multicolumn{2}{|c|}{$75 \cdot 2$} \\
\hline \multicolumn{7}{|l|}{ Plasma vitamins $(\mu \mathrm{mol} / \mathrm{l})$} \\
\hline$\beta$-Carotene & 0.83 & 0.33 & 0.40 & 0.09 & 0.18 & 0.05 \\
\hline$\alpha$-Carotene & 0.15 & 0.12 & 0.07 & 0.04 & 0.04 & 0.02 \\
\hline$\beta$-Cryptoxanthin & 0.43 & 0.33 & 0.30 & 0.21 & $0 \cdot 18$ & $0 \cdot 13$ \\
\hline Lycopene & 0.43 & 0.27 & 0.28 & 0.19 & 0.19 & 0.14 \\
\hline Lutein & 0.32 & 0.16 & 0.25 & 0.12 & 0.21 & $0 \cdot 11$ \\
\hline Zeaxanthin & 0.07 & 0.03 & 0.06 & 0.03 & 0.05 & 0.02 \\
\hline Retinol & 1.98 & 0.45 & 2.03 & 0.46 & $2 \cdot 01$ & 0.50 \\
\hline$\alpha$-Tocopherol & 31.4 & $7 \cdot 1$ & $29 \cdot 4$ & $6 \cdot 1$ & $26 \cdot 9$ & $6 \cdot 6$ \\
\hline Ascorbic acid & 55.0 & $20 \cdot 4$ & $49 \cdot 2$ & $20 \cdot 8$ & $44 \cdot 8$ & $22 \cdot 8$ \\
\hline
\end{tabular}

* For details of procedures, see p. 114.

†Allergy against pollen grains, domestic pets or house-dust.

lutein 0.77 . Correlations between the remaining carotenoids ranged from 0.19 to 0.48 .

Of the 652 participants, $5.2 \%$ chronically used multivitamin-mineral supplementation, $0.2 \%$ vitamin $A$ and vitamin A plus $\mathrm{D}, 3.5 \%$ vitamin $\mathrm{C}$ and $1.2 \%$ vitamin $\mathrm{E}$. The last 2 months of the observation period ( 2 months before blooddrawing) all participants refrained from any nutritional supplementation because of the upcoming intervention.

In total, 417 participants reported 754 events of common cold, 118 events of influenza, 108 events of sore throat, 43 events of pain in facial sinuses and 30 events of pneumonia. These events were combined to 1053 acute respiratory infections, which was the outcome in our present analysis. In $26 \%$ ( $n$ 235) of subjects there were no reports of respiratory infection during the previous 1 year. On average, 1.6 episodes were recorded per person per year.

A statistically significant inverse relationship was observed between $\beta$-carotene status and the incidence rate, but not severity, of the infections (Table 2). We observed a tendency for a similar relationship between the incidence rate of respiratory infections and $\alpha$-carotene status and $\beta$-cryptoxanthin status. The incidence rate ratios at high and intermediate concentrations were 0.79 (95\% CI $0.60-1.02)$ and $0.82(95 \%$ CI $0.66-1.01)$ for $\alpha$-carotene and 0.83 (95\% CI $0.64-1.07)$ and 0.78 (95\% CI $0.63-$ $0.97)$ for $\beta$-cryptoxanthin. When combinations of $\beta$-carotene, $\alpha$-carotene and $\beta$-cryptoxanthin were entered into one model, $\beta$-carotene turned out to have the greatest

Table 2. Incidence and severity of acute respiratory infections according to plasma $\beta$-carotene concentration in elderly Dutch subjects from 1997 to $1998^{*}$

\begin{tabular}{|c|c|c|c|c|c|c|c|}
\hline \multirow[b]{3}{*}{ Outcomes† } & \multirow[b]{3}{*}{$n$} & \multicolumn{5}{|c|}{$\beta$-Carotene concentration } & \multirow[b]{3}{*}{$P$ for trend } \\
\hline & & \multicolumn{2}{|r|}{ High } & \multicolumn{2}{|c|}{ Intermediate } & \multirow{2}{*}{$\frac{\text { Low }}{\text { OR }}$} & \\
\hline & & OR & $95 \% \mathrm{Cl}$ & OR & $95 \% \mathrm{Cl}$ & & \\
\hline Incidence rate (per person per year) & 652 & & 1.66 & & 1.73 & $2 \cdot 34$ & \\
\hline Incidence rate ratio & & 0.71 & $0.54,0.92$ & 0.74 & $0.60,0.91$ & 1.00 & 0.01 \\
\hline Staying in bed $\ddagger$ & 417 & 0.74 & $0.38,1.44$ & $1 \cdot 20$ & $0.71,2.03$ & 1.00 & $>0.2$ \\
\hline Medical consultation $\ddagger$ & 417 & 1.27 & $0.62,2.61$ & 1.44 & $0.79,2.64$ & 1.00 & $>0.2$ \\
\hline Episode-related medication $\ddagger$ & 417 & 1.33 & $0.73,2.43$ & 1.60 & $0.96,2.68$ & 1.00 & $>0.2$ \\
\hline
\end{tabular}

OR, Odds ratio.

* For details of subjects and procedures, see Table 1 and p. 114.

† All outcomes were corrected for gender, age, self-rated health and chronic obstructive pulmonary disease.

$\ddagger$ Adjusted OR $(95 \% \mathrm{Cl}$ ) of variables indicating infection severity, i.e. fever, staying in bed, medical consultation and use of medication were assessed in participants who experienced at least one respiratory infection (103 subjects in the high-, 206 in the intermediate-, and 108 in the low- $\beta$-carotene group). 
relative importance (results not shown). No significant relationship was observed between the variables indicating infection severity and $\alpha$-carotene or $\beta$-cryptoxanthin status. $P$ values of tests for trend for the severity variables showed no significant results.

The incidence rate ratios at high and intermediate concentrations were $1.24(95 \%$ CI $0.96-1.61)$ and 1.11 (95\% CI 0.89-1.40) for lycopene status, 1.13 (95\% CI $0.86-1.48)$ and $1.10(95 \%$ CI $0.88-1.40)$ for lutein status, and $1.06(95 \% \mathrm{CI} 0.83-1.35)$ and $0.92(95 \% \mathrm{CI}$ $0 \cdot 74-1 \cdot 15)$ for zeaxanthin status. Correspondingly, no significant relationship was observed between the variables indicating infection severity and lycopene, lutein and zeaxanthin status. $P$ values for tests for trend for the severity variables showed no significant results. Additional analysis to investigate the relationship between retinol (vitamin A) and the incidence of acute respiratory infections showed that the incidence rate ratio was $1.00(0.77-1.30)$ for high $v$. low retinol status and 0.98 (95\% CI $0.79-1.24)$ for intermediate $v$. low retinol status.

\section{Discussion}

In our large observational analysis in elderly people, a high plasma $\beta$-carotene status was associated with a lower incidence of acute respiratory infections, but not with a lower illness severity. No relationship was observed between plasma $\alpha$-carotene, $\beta$-cryptoxantin, lycopene, lutein and zeaxanthin status and the incidence and severity of the infections.

In the following discussion, we will address the possible threats to the internal validity in our present study. Error in the assessment of both exposure and outcome may lead to information bias. Participants and investigators were unaware of the carotenoid status at the time of outcome assessment, which makes differential error in the assessment of respiratory infections unlikely. Any error in the assessment of carotenoid concentrations and infectious diseases is expected to have been non-differential and could therefore only have led to underestimation of the association. One might wonder whether the plasma carotenoid concentration of elderly people is stable over a 1-year period. Van-Kappel et al. (2001) have shown that serum carotenoids were highly reproducible between 1- and 2-year repeated measurements. We therefore have no reason to question the representativeness of the observed concentrations for the previous year.

Incidence in this retrospective study was in accordance with incidences reported in prospective studies that were effectively validated by nurse or general practitioner assessment, or by microbiological analyses (Falsey et al. 1995; Nicholson et al. 1997; Graat et al. 2002). Although we cannot rule out misclassification of the self-recorded infections, e.g. exacerbations of chronic obstructive pulmonary disease could have been indistinguishable from symptoms during respiratory infections, this supports the accuracy of self-reporting of infections that occurred during the previous 1 year.

Bias by confounding was appropriately addressed during the data analysis phase. Multivariate analyses were adjusted for several confounders. Bias might have occurred by some variables that we did not measure, e.g. intake of fruits and vegetables, and cognitive function.

The average plasma carotenoid concentrations and corresponding standard deviations as measured in our present population were similar to levels in elderly Europeans, except for the average lycopene concentration that was higher in our present population (Haller et al. 1996). We therefore suppose that our range of carotenoid concentrations was sufficiently large to show an effect.

We observed a beneficial association only for $\beta$-carotene, and not for the other carotenoids. A high plasma $\beta$-carotene concentration has been associated with increased lung function (Grievink et al. 2000). Lung tissue could be the relevant target tissue and plasma concentrations may serve as a more accessible biomarker of carotenoid status of human lung tissue and broncho-alveolar lavage cells (Redlich et al. 1996, 1998). Previous research demonstrated quantifiable levels of various carotenoids in human lung tissue, i.e. lutein, cryptoxanthin, $\alpha$-carotene, $\beta$-carotene and lycopene. The concentration of $\beta$-carotene was higher compared with other carotenoids, but it was not reported whether this was significant or not (Schmitz et al. 1991). It is possible that our observed favourable association of $\beta$-carotene was due to its higher concentrations in lung tissue.

$\beta$-Carotene is a precursor of retinol. No clear favourable effects of vitamin A supplementation on infectious disease or immune response have been observed in elderly people in developed countries, which is in accordance with our present results (Murphy et al. 1992; Fortes et al. 1998). Beneficial effects of vitamin A supplementation on infectious diseases were predominantly observed in children of developing countries; these children were sometimes marginally deficient in vitamin A (Semba, 1994). Although we cannot exclude the possibility that $\beta$-carotene is inversely related to respiratory illness by influencing plasma retinol concentration, we suppose that this mechanism is less plausible.

We did not observe relationships between $\alpha$-carotene, $\beta$-cryptoxanthin, lycopene, lutein and zeaxanthin, and acute respiratory infections. $\alpha$-Carotene and $\beta$-cryptoxanthin have never been reported in relation to incidence or severity of acute respiratory infections, nor in relation to human immune response. Literature concerning lycopene, lutein and zeaxanthin, and immune function is scarce. No clear associations of lycopene, lutein and zeaxanthin were observed with blood monocytes and T-helper cell activities (Jyonouchi et al. 1996; Hughes et al. 2000; Corridan et al. 2001). Correspondingly, no effect of tomato juice, with lycopene being the predominant carotenoid, on cell-mediated immunity was shown (Watzl et al. 2000). Those findings support our null-findings on respiratory infections. In contrast, Watzl et al. (1999) showed improved T-lymphocyte function by tomato juice consumption in subjects consuming a diet low in carotenoids.

One may question whether information on plasma carotenoid concentration can be extrapolated to the intake of certain foods. Some studies have shown a significant relationship between dietary intake of fruits and vegetables and plasma carotenoid concentration (Rock et al. 1997; Broekmans et al. 2000), whereas others did not 
(Tucker et al. 1999; Jansen, 2001; van-Kappel et al. 2001). Fruits and vegetables do not only possess carotenoids, but also various other bioactive compounds such as flavonoids. If it had consistently been shown that a strong relationship exists between intake of fruits and vegetables and plasma carotenoid concentrations, we might have translated our findings into dietary advice. Because of inconsistency in the literature, such extrapolation is not possible.

Our present findings suggest that elderly persons with a high plasma $\beta$-carotene concentration may have a lower occurrence of acute respiratory infections. It would be interesting to evaluate the effect of fruits and vegetables or $\beta$-carotene supplementation on the infections in a trial. However, one should be cautious about high-dose $\beta$-carotene supplementation, since increased mortality has been reported after such supplementation.

\section{Acknowledgements}

We would like to thank The Netherlands Organization for Health Research and Development (ZonMw), The Hague, The Netherlands (contract number 28-2639) for their financial support. We are grateful to Roche Vitamins Europe, Ltd, Basel, Switzerland for performing all vitamin analyses. We thank Frouwkje de Waart and Esther Pallast for their contribution at the start of the trial, and Francis van Rooij and Marga van der Steen for their practical assistance.

\section{References}

Aebischer CP, Schierle J \& Schuep W (1999) Simultaneous determination of retinol, tocopherols, carotene, lycopene, and xanthophylls in plasma by means of reversed-phase high-performance liquid chromatography. Methods Enzymol 299, 348-362.

Broekmans WMR, Klopping KI, Schuurman CRWC, Verhagen H, Van-den Berg H, Kok FJ \& Van Poppel G (2000) Fruits and vegetables increase plasma carotenoids and vitamins and decrease homocysteine in humans. J Nutr 130, 1578-1583.

Carrat F, Tachet A, Rouzioux C, Housset B \& Valleron AJ (1999) Evaluation of clinical case definitions of influenza, detailed investigation of patients during the 1995-1996 epidemic in France. Clin Infect Dis 28, 283-290.

Corridan BM, O'Donoghue M, Hughes DA \& Morrissey PA (2001) Low-dose supplementation with lycopene or beta-carotene does not enhance cell-mediated immunity in healthy freeliving elderly humans. Eur J Clin Nutr 55, 627-635.

Daudu PA, Kelley DS, Taylor PC, Burri BJ \& Wu MM (1994) Effect of a low beta-carotene diet on the immune functions of adult women. Am J Clin Nutr 60, 969-972.

Falsey AR, McCann RM, Hall WJ, Tanner MA, Criddle MM, Formica MA, Irvine CS, Kolassa JE, Barker WH \& Treanor JJ (1995) Acute respiratory tract infection in daycare centers for older persons. J Am Geriatr Soc 43, 30-36.

Fortes C, Forastiere F, Agabiti N, et al. (1998) The effect of zinc and vitamin A supplementation on immune response in an older population. J Am Geriatr Soc 46, 19-26.

Fuller CJ, Faulkner H, Bendich A, Parker RS \& Roe DA (1992) Effect of beta-carotene supplementation on photosuppression of delayed-type hypersensitivity in normal young men. Am J Clin Nutr 56, 684-690.
Graat JM, Schouten EG \& Kok FJ (2002) Effect of daily vitamin $\mathrm{E}$ and multivitamin-mineral supplementation on acute respiratory tract infections in elderly persons: a randomized controlled trial. J Am Med Assoc 288, 715-721.

Grievink L, de-Waart FG, Schouten EG \& Kok FJ (2000) Serum carotenoids, alpha-tocopherol, and lung function among Dutch elderly. Am J Respir Crit Care Med 161, 790-795.

Haller J, Weggemans RM, Lammi KC \& Ferry M (1996) Changes in the vitamin status of elderly Europeans: plasma vitamins A, E, B-6, B-12, folic acid and carotenoids. SENECA Investigators. Eur J Clin Nutr 50, Suppl. 2, S32-S46.

Hemila H, Kaprio J, Albanes D, Heinonen OP \& Virtamo J (2002) Vitamin C, vitamin E, and beta-carotene in relation to common cold incidence in male smokers. Epidemiology 13, $32-37$.

Hess D, Keller HE, Oberlin B, Bonfanti R \& Schuep W (1991) Simultaneous determination of retinol, tocopherols, carotenes and lycopene in plasma by means of high-performance liquid chromatography on reversed phase. Int J Vitam Nutr Res $\mathbf{6 1}$, 232-238.

Hughes DA (2001) Dietary carotenoids and human immune function. Nutrition 17, 823-827.

Hughes DA, Wright AJA, Finglas PM, Polley AC, Bailey AL, Astley SB \& Southon S (2000) Effects of lycopene and lutein supplementation on the expression of functionally associated surface molecules on blood monocytes from healthy male nonsmokers. J Infect Dis 182, Suppl. 1, S11-S15.

Jansen CJF (2001) Fruits and Vegetables and the Risk of Epithelial Cancer. $\mathrm{PhD}$ Thesis, Wageningen University.

Jyonouchi H, Sun S, Mizokami M \& Gross MD (1996) Effects of various carotenoids on cloned, effector-stage T-helper cell activity. Nutr Cancer 26, 313-324.

Khachik F, Beecher GR \& Smith JCJ (1995) Lutein, lycopene, and their oxidative metabolites in chemoprevention of cancer. $J$ Cell Biochem 22, 236-246.

Miller RA (1996) The aging immune system: primer and prospectus. Science 273, 70-74.

Murata T, Tamai H, Morinobu T, Manago M, Takenaka $\mathrm{H}$, Hayashi K \& Mino M (1994) Effect of long-term administration of beta-carotene on lymphocyte subsets in humans. Am J Clin Nutr 60, 597-602.

Murphy S, West-KP J, Greenough WB, Cherot E, Katz J \& Clement L (1992) Impact of vitamin A supplementation on the incidence of infection in elderly nursing-home residents: a randomized controlled trial. Age Ageing 21, 435-439.

Nicholson KG, Kent J, Hammersley V \& Cancio E (1997) Acute viral infections of upper respiratory tract in elderly people living in the community: comparative, prospective, population based study of disease burden. Br Med J 315, 1060-1064.

Redlich CA, Blaner WS, Van-Bennekum AM, Chung JS, Clever SL, Holm CT \& Cullen MR (1998) Effect of supplementation with beta-carotene and vitamin A on lung nutrient levels. Cancer Epidemiol Biomarkers Prev 7, 211-214.

Redlich CA, Grauer JN, Van-Bennekum AM, Clever SL, Ponn RB \& Blaner WS (1996) Characterization of carotenoid, vitamin A, and alpha-tocopheral levels in human lung tissue and pulmonary macrophages. Am J Respir Crit Care Med 154, 1436-1443.

Ringer TV, DeLoof MJ, Winterrowd GE, Francom SF, Gaylor SK, Ryan JA, Sanders ME \& Hughes GS (1991) Beta-carotene's effects on serum lipoproteins and immunologic indices in humans. Am J Clin Nutr 53, 688-694.

Rock CL, Flatt SW, Wright FA, Faerber S, Newman V, Kealey S \& Pierce JP (1997) Responsiveness of carotenoids to a high vegetable diet intervention designed to prevent breast cancer recurrence. Cancer Epidemiol Biomarkers Prev 6, 617-623.

Santos MS, Leka LS, Ribaya-Mercado JD, Russell RM, Meydani M, Hennekens CH, Gaziano JM \& Meydani SN 
(1997) Short- and long-term beta-carotene supplementation do not influence $\mathrm{T}$ cell-mediated immunity in healthy elderly persons. Am J Clin Nutr 66, 917-924.

Santos MS, Meydani SN, Leka L, Wu D, Fotouhi N, Meydani M, Hennekens CH \& Gaziano JM (1996) Natural killer cell activity in elderly men is enhanced by beta-carotene supplementation. Am J Clin Nutr 64, 772-777.

Schmitz HH, Poor CL, Wellman RB \& Erdman JW (1991) Concentrations of selected carotenoids and vitamin $\mathrm{A}$ in human liver, kidney and lung tissue. J Nutr 121, 1613-1621.

Semba RD (1994) Vitamin A, immunity, and infection. Clin Infect Dis 19, 489-499.

Tannock GA, Reid AL, Gillett SM, et al. (1993) A study of respiratory infections in a healthy adult population during the 1987 Australian winter. Fam Pract 10, 378-386.

Thurnham DI (1994) Carotenoids, functions and fallacies. Proc Nutr Soc 53, 77-87.

Tucker KL, Chen H, Vogel S, Wilson PW, Schaefer EJ \& Lammi-Keefe CJ (1999) Carotenoid intakes, assessed by dietary questionnaire, are associated with plasma carotenoid concentrations in an elderly population. J Nutr 129, 438-445.

Van-Kappel AL, Steghens JP, Zeleniuch-Jacquotte A, Chajes V, Toniolo P \& Riboli E (2001) Serum carotenoids as biomarkers of fruit and vegetable consumption in the New York Women's Health Study. Public Health Nutr 4, 829-835.
Van-Poppel G, Spanhaak S \& Ockhuizen T (1993) Effect of betacarotene on immunological indexes in healthy male smokers. Am J Clin Nutr 57, 402-407.

Vogel S, Contois JH, Tucker KL, Wilson PW, Schaefer EJ \& Lammi KC (1997) Plasma retinol and plasma and lipoprotein tocopherol and carotenoid concentrations in healthy elderly participants of the Framingham Heart Study. Am J Clin Nutr 66, 950-958.

Vuilleumier JP \& Keck E (1989) Fluorometric assay of vitamin C in biological materials using a centrifugal analyser with fluorescence attachment. J Micronutr Anal 5, 25-34.

Watson RR, Prabhala RH, Plezia PM \& Alberts DS (1991) Effect of beta-carotene on lymphocyte subpopulations in elderly humans: evidence for a dose-response relationship [published erratum appears in Am J Clin Nutr (1991) 53, 988]. Am J Clin Nutr 53, 90-94.

Watzl B, Bub A, Blockhaus M, Herbert BM, Luhrmann PM, Neuhauser-Berthold M \& Rechkemmer G (2000) Prolonged tomato juice consumption has no effect on cell-mediated immunity of well-nourished elderly men and women. $J$ Nutr 130, 1719-1723.

Watzl B, Bub A, Brandstetter BR \& Rechkemmer G (1999) Modulation of human T-lymphocyte functions by the consumption of carotenoid-rich vegetables. Br J Nutr 82, 383-389. 